\title{
PENGARUH ADMIXTURE TERHADAP CAMPURAN BETON K 350 DITINJAU DARI KUAT TEKAN BETON
}

\author{
Rida Respati \\ Program Studi Teknik Sipil, Universitas Muhammadiyah Palangkaraya
}

\begin{abstract}
ABSTRAK
Dalam penelitian ini, ingin dilakukan percobaan untuk mengetahui kuat tekan beton mutu sedang K-350 dengan bahan tambah MASTER RHEOBUILD 6 yang mana fungsinya adalah untuk mempercepat pengerasan, meningkatkan mutu beton, mengurangi pemakaian air dan menaikkan nilai slump. Akan tetapi harus menjadi perhatian bahwa kesalahan dalam dosis dan cara pemakaian bahan tambah dapat merugikan terhadap kualitas beton. Hasil dari penelitian menunjukkan, bahwa penambahan $0.25,0.5$, dan 0.75 liter per 50 $\mathrm{kg}$ semen dapat meningkatkan kuat tekan beton. Kuat tekan beton dengan penambahan 0.25 liter $/ 50 \mathrm{~kg}$ semen mengalami kenaikan $362,67 \mathrm{~kg} / \mathrm{cm}^{2}$ dari kuat tekan beton normal $350,58 \mathrm{~kg} / \mathrm{cm}^{2}$. Penambahan $0.5 \mathrm{liter} / 50 \mathrm{~kg}$ semen mengalami kenaikan lagi hingga $373,24 \mathrm{~kg} / \mathrm{cm}^{2}$, dan penambahan 0.75 liter $/ 50 \mathrm{~kg}$ semen mengalami kenaikan kuat tekan beton menjadi $379,29 \mathrm{~kg} / \mathrm{cm}^{2}$ dari beton normal. Perbandingan kuat tekan sebelum dan setelah penambahan admixture dengan kenaikan 3,45\% pada penambahan 0,25 liter $/ 50 \mathrm{~kg}$ semen, 6,47\% pada penambahan 0,5 liter $/ 50 \mathrm{~kg}$ semen dan $8,19 \%$ pada penambahan 0,75 liter $/ 50 \mathrm{~kg}$ semen.
\end{abstract}

Kata kunci: campuran beton, kuat tekan, bahan tambah admixture 


\section{PENDAHULUAN}

Beton merupakan unsur yang sangat penting, mengingat fungsinya sebagai salah satu pembentuk struktur yang paling banyak digunakan oleh masyarakat. Keadaan ini dapat dimaklumi, karena sistem konstruksi beton mempunyai banyak kelebihan jika dibandingkan dengan bahan lain. Dalam praktek sering terjadi dikehendaki beton yang dikerjakan mempunyai sifat tertentu sesuai dengan kebutuhan. Adanya keperluan membongkar atau melepas cetakan lebih awal akan membutuhkan beton yang mempunyai sifat lebih cepat mengeras dan mencapai kekuatan awal lebih tinggi. Untuk memperoleh beton dengan sifat-sifat tertentu diperlukan bahan tambah yang dapat mengubah sifat alami beton. Bahan tambah sendiri dapat berupa serbuk atau cairan. Bahan tambahan adalah bahan selain unsur pokok beton (air, semen dan agregat) yang ditambahkan pada adukan beton, sebelum, segera atau selama pengadukan beton.

Penelitian-penelitian telah banyak dilakukan untuk memperoleh suatu penemuan alternatif penggunaan konstruksi beton dalam berbagai bidang secara tepat dan efisien, sehingga akan diperoleh mutu beton yang lebih baik.

\section{KAJIAN PUSTAKA}

\section{Kajian Pustaka}

Henny (2009) melakukan penelitian tentang "OPTIMASI PENAMBAHAN ADMIXTURE DAN ADDITIVE SF100-MB-SF PADA BETON MUTU TINGGI". Dari hasil penelitian menunjukan bahwa penggunaan bahan admixture dan additive dapat memperbaiki sifat dan menambah kuat tekan beton sesuai dengan yang diinginkan.

\section{Materi Penyusun Beton}

\section{Semen Portland}

Semen Portland adalah semen hidrolis yang dihasilkan dangan cara menggilingkan terak semen portland terutama yang terdiri atas kalsium silikat yang bersifat hidrolis dan digiling bersama-sama dengan bahan tambahan berupa satu atau lebih bentuk kristal senyawa kalsium sulfat dan boleh ditambah dengan bahan tambahan lain. (SNI 152049-2004).
Tabel 1. Jenis Semen Portland di Indonesia Sesuai SNI 15- 2049-2004

\begin{tabular}{|c|l|}
\hline Jenis & Penggunaan \\
\hline I & $\begin{array}{l}\text { Konstruksi biasa dimana persyaratan } \\
\text { yang khusus tidak diperlukan }\end{array}$ \\
\hline II & $\begin{array}{l}\text { Konstruksi dimana diperlukan } \\
\text { ketahanan terhadap sulfat dan panas } \\
\text { hidrasi sedang }\end{array}$ \\
\hline III & $\begin{array}{l}\text { Konstruksi dimana dituntut memiliki } \\
\text { kekuatan awal yang tinggi setelah } \\
\text { pengikatan terjadi }\end{array}$ \\
\hline IV & $\begin{array}{l}\text { Konstruksi dimana dituntut } \\
\text { menghasilkan panas hidrasi yang } \\
\text { rendah }\end{array}$ \\
\hline V & $\begin{array}{l}\text { Konstruksi dimana dituntut memiliki } \\
\text { ketahanan yang tinggi } \\
\text { terhadap sulfat }\end{array}$ \\
\hline
\end{tabular}

Sumber: SNI 15-2049-2004

\section{Agregat halus}

Menurut Kardiyono (1996), agregat halus adalah agregat yang berbutir kecil (antara $0,15 \mathrm{~mm}$ dan $5 \mathrm{~mm}$ ). Dalam pemilihan agregat halus harus benar-benar memenuhi persyaratan yang telah ditentukan. Karena sangat menentukan dalam hal kemudahan pengerjaan (workability), kekuatan (strength), dan tingkat keawetan (durability) dari beton yang dihasilkan.

Menurut PBI 1971 (NI-2) pasal 33, syaratsyarat agregat halus (pasir) adalah sebagai berikut:

1) Agregat halus terdiri dari butiran-butiran tajam dan keras, bersifat kekal dalam arti tidak pecah atau hancur oleh pengaruh cuaca, seperti panas matahari dan hujan.

2) Agregat halus tidak boleh lumpur lebih dari $5 \%$ terhadap jumlah berat agregat kering. Apabila kandungan lumpur lebih dari 5\%, agregat halus harus dicuci terlebih dahulu.

3) Agregat halus tidak boleh mengandung bahan bahan organik terlalu banyak. Hal demikian dapat dibuktikan dengan percobaan warna dari Abrams Header dengan menggunakan larutan $\mathrm{NaOH}$.

4) Agregat halus terdiri dari butiran-butiran yang beranekaragam besarnya dan apabila diayak dengan susunan ayakan yang ditentukan dalam pasal 3.5 ayat 1 (PBI 1971), harus memenuhi syarat sebagai berikut: 
a) Sisa di atas ayakan $4 \mathrm{~mm}$, harus minimum $2 \%$ berat.

b) Sisa di atas ayakan $1 \mathrm{~mm}$, harus minimum $10 \%$ berat. Sisa di atas ayakan $0,25 \mathrm{~mm}$, harus berkisar antara $80 \%-90 \%$ berat

Tabel 2. Batas Susunan Agregat Halus

\begin{tabular}{|c|c|c|c|c|}
\hline \multirow{2}{*}{$\begin{array}{c}\text { Ukuran } \\
\text { Saringan } \\
(\mathrm{mm})\end{array}$} & \multicolumn{4}{|c|}{ Prosentase lolos saringan } \\
\cline { 2 - 5 } & $\begin{array}{c}\text { Daerah } \\
\text { I }\end{array}$ & $\begin{array}{c}\text { Daerah } \\
\text { II }\end{array}$ & $\begin{array}{c}\text { Daerah } \\
\text { III }\end{array}$ & $\begin{array}{c}\text { Daerah } \\
\text { IV }\end{array}$ \\
\hline 10,00 & 100 & 100 & 100 & 100 \\
\hline 4,80 & $90-100$ & $90-100$ & $90-100$ & $95-100$ \\
\hline 2,40 & $60-95$ & $75-100$ & $85-100$ & $95-100$ \\
\hline 1,20 & $30-70$ & $55-90$ & $75-100$ & $90-100$ \\
\hline 0,60 & $15-34$ & $35-59$ & $60-79$ & $80-100$ \\
\hline 0,30 & $5-20$ & $8-30$ & $12-40$ & $15-50$ \\
\hline 0,15 & $0-10$ & $0-10$ & $0-10$ & $0-15$ \\
\hline
\end{tabular}

Sumber: Teknologi Beton, Kardiyono Tjokrodimu

\section{Agregat Kasar}

Menurut PBI 1971 NI-2 yang digunakan untuk beton merupakan kerikil hasil disintergrasi dari batu-batuan atau berupa batu pecah (split) yang diperoleh dair alat pemecah batu, dengan syarat ukuran butirannya lolos ayakan $38,1 \mathrm{~mm}$ dan tertahan di ayakan $4,76 \mathrm{~mm}$. Pada umumnya yang dimaksudkan dengan agregat kasar adalah agregat dengan besar butir lebih dari $5 \mathrm{~mm}$. Agregat kasar yang digunakan pada campuran beton harus memenuhi persyaratan-persyaratan sebagai berikut:

1) Agregat kasar adalah agregat dengan besar butiran lebih dari $5 \mathrm{~mm}$. Sesuai dengan syaratsyarat pengawasan mutu agregat untuk berbagai mutu beton maka agregat kasar harus memenuhi syarat.

2) Agregat kasar harus terdiri dari butir-butir yang keras dan tidak berpori. Agregat kasar yang mengandung butir-butir pipih hanya dapat dipakai apabila jumlah butir-butir pipih tersebut tidak melampaui $20 \%$ dari berat agregat seluruhnya. Butir-butir kasar harus bersifat kekal yang berarti tidak pecah atau hancur akibat pengaruh cuaca seperti hujan dan terik matahari.

3) Agregat kasar tidak boleh mengandung lumpur lebih dari $1 \%$ (ditentukan terhadap berat
kering).Yang diartikan dengan lumpur adalah bagian-bagian yang dapat melalui/lolos ayakan $0,063 \mathrm{~mm}$. Apabila kadar lumpur melampaui 1 $\%$, maka agregat kasar harus dicuci.

4) Agregat kasar tidak boleh mengandung bahanbahan yang dapat merusak beton, seperti zatzat yang aktif terhadap alkali.

5) Kekerasan dari butir-butir agregat kasar diperiksa dengan mesin pengaus Los Angeles dimana tidak boleh terjadi kehilangan berat melebihi $5 \%$.

6) Agregat kasar harus terdiri dari butir-butir yang beraneka ragam dan apabila diayak, harus memenuhi syarat-syarat sebagai berikut:

a) Sisa di atas ayakan 31,5 $\mathrm{mm}$ harus $0 \%$ berat.

b) Sisa di atas ayakan $4 \mathrm{~mm}$ harus berkisar antara $90 \%$ dan $98 \%$.

7) Selisih antara sisa-sisa kumulatif ayakan yang berurutan adalah Berat butir agregat maksimum tidak boleh lebih dari $1 / 5$ jarak terkecil antara bidang-bidang samping dari cetakan, 1/3 dari tebal plat atau 3/4 dari jarak bersih minimum di antara batang-batang atau berkas tulangan. Penyimpangan dari batasan ini diijinkan apabila menurut pengawas ahli, cara pengecoran beton adalah sedemikian rupa sehingga menjamin tidak terjadinya sarangsarang kerikil. Batasan Modulus kehalusan kerikil: $5,5 \leq \mathrm{FM} \leq 7,5$.

Air

Air berguna untuk melarutkan semen sehingga akan menghasilkan senyawa hidrat arang yang dapat mengeras. Dalam konstruksi beton, air adalah bahan campuran yang turut menentukan mutu dari suatu beton. Oleh sebab itu pemakaian air dalam campuran beton harus diteliti terlebih dahulu agar jangan mengurangi mutu beton yang dihasilkan. Jumlah air yang dipakai untuk membuat adukan beton dapat ditentukan dengan ukuran isi atau ukuran berat dan harus dilakukan dengan tepat.

Menurut PBBI 1971 N.I.-2, pemakaian air untuk beton tersebut sebaiknya memenuhi persyaratan sebagai berikut:

1) Air harus bersih

2) Tidak mengandung lumpur

3) Tidak mengandung garam-garam yang dapat merusak beton seperti asam, zat organic

4) Tidak mengandung minyak dan alkali

5) Tidak mengandung senyawa asam. 


\section{Bahan Tambahan (Admixture)}

Bahan tambahan adalah bahan selain unsur pokok beton (air, semen dan agregat) yang ditambahkan pada adukan beton, sebelum, segera atau selama pengadukan beton. Tujuan pemberian bahan tambah adalah untuk mengubah satu atau lebih sifat beton sewaktu masih dalam keadaan segar atau setelah mengeras, misalnya untuk mempercepat pengerasan, menambah encer adukan, menambah kuat tekan, menambah kuat tarik, mengurangi sifat getas, mengurangi retak-retak pengerasan, mengurangi porositas, mengurangi rembesan, permeabilitas, absorpsi dan sebagainya. Secara umum bahan tambah yang digunakan dalam beton dapat dibedakan menjadi dua yaitu bahan tambah yang bersifat kimiawi (chemical admixture) dan bahan tambah yang bersifat mineral (additive). Menurut standar ASTM, terdapat 7 jenis bahan tambah kimia, yaitu:

1) Tipe A, Water-Reducing Admixtures.

Bahan tambah yang berfungsi untuk mengurangi penggunaan air pengaduk untuk menghasilkan beton dengan konsistensi tertentu. Dengan menggunakan jenis bahan tambah ini akan dapat dicapai tiga hal, yaitu meningkatkan workbility, menambah kuat tekan beton dan mengurangi biaya.

2) Tipe B, Retarding Admixtures.

Bahan tambah yang berfungsi untuk memperlambat proses waktu pengikatan beton. Biasanya digunakan pada saat kondisi cuaca panas, memperpanjang waktu untuk pemadatan, pengangkutan dan pengecoran.

3) Tipe C, Accelerating Admixtures.

Jenis bahan tambah yang berfungsi untuk mempercepat proses pengikatan dan pengembangan kekuatan awal beton. Bahan ini digunakan untuk memperpendek waktu pengikatan semen sehingga mempecepat pencapaian kekuatan beton. Yang termasuk jenis accelerator adalah: kalsium klorida, bromide, karbonat dan silikat. Pada daerahdaerah yang menyebabkan korosi tinggi tidak dianjurkan menggunakan accelerator jenis kalsium klorida. Dosis maksimum yang dapat ditambahkan pada beton adalah sebesar $2 \%$ dari berat semen.

4) Tipe D, Water Reducing and Retarding Admixtures.

Jenis bahan tambah yang berfungsi ganda yaitu untuk mengurangi jumlah air pengaduk yang diperlukan pada beton tetapi tetap memperoleh adukan dengan konsistensi tertentu sekaligus memperlambat proses pengikatan awal dan pengerasan beton. Dengan menambahkan bahan ini ke dalam beton, maka jumlah semen dapat dikurangi sebanding dengan jumlah air yang dikurangi. Bahan ini berbentuk cair sehingga dalam perencanaan jumlah air pengaduk beton, maka berat admixture ini harus ditambahkan sebagai berat air total pada beton.

5) Tipe E, Water Reducing and Accelerating Admixtures.

Jenis bahan tambah yang berfungsi ganda yaitu untuk mengurangi jumlah air pengaduk yang diperlukan pada beton tetapi tetap memperoleh adukan dengan konsistensi tertentu sekaligus mempercepat proses pengikatan awal dan pengerasan beton. Beton yang ditambah dengan bahan tambah jenis ini akan dihasilkan beton dengan waktu pengikatan yang cepat serta kadar air yang rendah tetapi tetap workable. Dengan menggunakan bahan ini diinginkan beton yang mempunyai kuat tekan tinggi dengan waktu pengikatan yang lebih cepat (beton mempunyai kekuatan awal yang tinggi).

6) Tipe F, Water Reducing, High Range Admixtures.

Jenis bahan tambah yang berfungsi untuk mengurangi jumlah air pencampur yang diperlukan untuk menghasilkan beton dengan konsistensi tertentu, sebanyak $12 \%$ atau lebih. Dengan menmbahkan bahan ini ke dalam beton, diinginkan untuk mengurangi jumlah air pengaduk dalam jumlah yang cukup tinggi sehingga diharapkan kekuatan beton yang dihasilkan tinggi dengan jumlah air sedikit, tetapi tingkat kemudahan pekerjaan (workability) juga lebih tinggi. Bahan tambah jenis ini berupa superplasticizer. Yang termasuk jenis superplasticizer adalah kondensi sulfonat melamine formaldehyde dengan kandungan klorida sebesar 0,005 \%, sulfonat nafthalin formaldehyde, modifikasi lignosulphonat tanpa kandungan klorida. Jenis bahan ini dapat mengurangi jumlah air pada campuran beton dan meningkatkan slump beton sampai $208 \mathrm{~mm}$. Dosis yang dianjurkan adalah $1 \%-2 \%$ dari berat semen.

7) Tipe G, Water Reducing, High Range Retarding Admixtures.

Jenis bahan tambah yang berfungsi untuk mengurangi jumlah air pencampur yang diperlukan untuk menghasilkan beton dengan 
konsistensi tertentu, sebanyak $12 \%$ atau lebih sekaligus menghambat pengikatan dan pengerasan beton. Bahan ini merupakan gabungan superplasticizer dengan memperlambat waktu ikat beton. Digunakan apabila pekerjaan sempit karena keterbatasan sumberdaya dan ruang kerja.

\section{MasterRheobuild 6}

MasterRheobuild 6 merupakan bahan tambah (admixture) tipe F yang diproduksi oleh PT BASF Indonesia dan memenuhi persyaratan ASTM C494 untuk pencamuran dan peremajaan tinggi. MasterRheobuild 6 adalah suatu cairan admixture yang berisi suatu bahan Non- Air Entraining Plasticiser yang berfungsi untuk mempertinggi mutu beton, mengurangi pemakaian air, serta menaikkan nilai slump. Dengan kenaikan nilai slump maka kadar air yang digunakan pada campuran beton dapat berkurang. Bila kadar air yang digunakan berkurang maka dapat mengurangi pori yang terdapat pada beton sehingga beton yang dihasilkan lebih mampat.

Pemakaian air terlalu banyak akan menurunkan mutu beton karena semakin banyak air berarti pori yang terjadi dalam beton akan banyak sehingga beton bersifat porous, kelebihan air juga akan mengakibatkan bleeding yaitu pengaliran air keatas permukaan beton dengan membawa semen sehingga akan membentuk lapisan tipis di permukaan beton yang dikenal dengan laitance (Tjokrodimuljo, 1996).

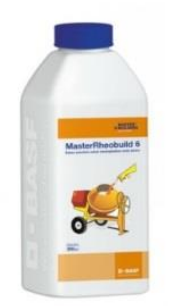

Gambar 1. Bahan Tambahan "MasterRheobuild 6"

\section{METODE PENELITIAN}

Sebagai peneliti ilmiah, maka penelitian ini harus dilaksanakan secara sisitematika dan urutan yang jelas serta teratur sehingga nantinya diperoleh hasil yang memuaskan dan dapat dipertanggung jawabkan. Pelaksanaan penelitian ini dibagikan dalam beberapa tahap, yaitu: a. Tahap I

Tahap ini disebut tahap persiapan. Pada tahap ini seluruh peralatan dan bahan yang dibutuhkan dalam penelitian ini dipersiapkan terlebih dahulu agar penelitian dapat berjalan dengan lancar.

b. Tahap II

Tahap ini disebut tahap uji bahan. Pada tahap ini dilakukan penelitian terhadap agregat halus, agregat kasar dan air. Hal ini dilakukan untuk mengetahui sifat dan karekteristik bahan tersebut. Selain itu untuk mengetahui apakah bahan tersebut memenuhi persyaratan atau tidak.

c. Tahap III

Tahap ini disebut tahap pembuatan benda uji. Pada tahap ini dilakukan pekerjaan sebagai berikut:

Penetapan rancang campur (mix design) adukan beton berdasarkan data-data yang diperoleh pada tahap II.

1) Pembuatan adukan beton.

2) Pemeriksaan nilai slump.

3) Pembuatan benda uji

d. Tahap IV

Pada tahap ini benda-benda uji ini selanjutnya dirawat dengan cara direndam sampai masa pengujian kuat tekan dilakukan, yaitu umur 7 hari, 14 hari dan 28 hari.

e. Tahap V

Pada tahap ini, data yang diperoleh dari hasil pengujian dianalisa untuk mendapatkan suatu kesimpulan hubungan antara variabel-variabel yang diteliti dalam penelitian.

f. Tahap VI

Disebut tahap pengambilan kesimpulan. Pada tahap ini, data yang telah analisa dibuat suatu kesimpulan yang berhubungan dengan penelitian.

\section{HASIL DAN PEMBAHASAN}

\section{Ukuran Butir Agregat}

Pengujian ini dilakukan untuk menentukan pembagian butir (gradasi) agregat halus dan agregat kasar, yang mana hasil pemeriksaannya dapat dilihat pada Gambar 2 dan 3. 


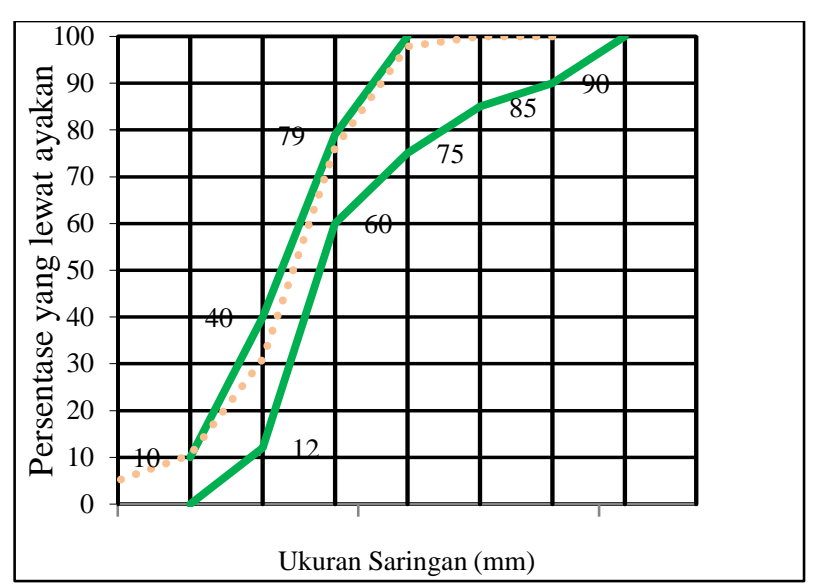

Sumber: Data uji laboratorium 2018

Gambar 2. Grafik Ukuran Butir Agregat Halus

Pada Gambar 2 dapat dilihat ukuran butir pasir Tangkiling yang termasuk kedalam gradasi daerah no. 3 atau termasuk kedalam kategori pasir agak halus menurut SNI 03-2824-2000.

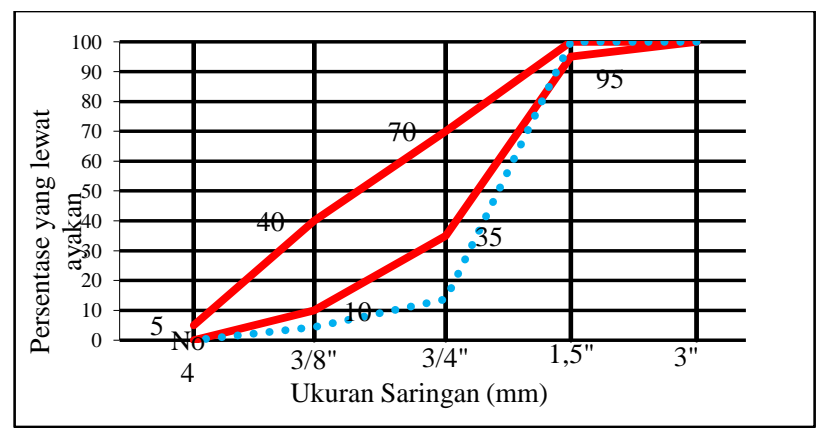

Sumber: Data uji laboratorium 2018

Gambar 3. Grafik Ukuran Butir Agregat Kasar

Pada Gambar 3 dapat dilihat ukuran butir untuk batu merak termasuk kedalam batas gradasi ukuran maksimum $40 \mathrm{~mm}$ menurut SNI 03-28242000

\section{Berat Jenis Agregat}

Pengujian ini bertujuan untuk menentukan berat jenis dari semua agregat halus dan kasar serta penyerapan airnya, hasil pengujian dapat dilihat pada Tabel 3 berikut.
Tabel 3. Pengujian Berat Jenis dan Penyerapan Air

\begin{tabular}{|c|c|c|c|}
\hline Material & $\begin{array}{c}\text { Berat } \\
\text { Jenis } \\
\left(\mathbf{g r} / \mathbf{c m}^{3}\right)\end{array}$ & $\begin{array}{c}\text { SSD } \\
\left(\mathbf{g r} / \mathbf{c m}^{3}\right)\end{array}$ & $\begin{array}{c}\text { Penyerapan } \\
\text { Air (\%) }\end{array}$ \\
\hline $\begin{array}{c}\text { Pasir } \\
\text { Tangkiling }\end{array}$ & 2,695 & 2,711 & 0,604 \\
\hline Batu Merak & 2,602 & 2,646 & 1,675 \\
\hline
\end{tabular}

Sumber: Data uji laboratorium 2018

\section{Kadar Lumpur}

Pengujian ini bertujuan untuk mengetahui kandungan lumpur dari agregat, sebelum dilakukan pencampuran karena lumpur dalam agregat akan mempengaruhi kuat tekan beton, jika kadar lumpur pada agregat melebihi syarat yang ditentukan, maka agregat harus terlebih dahulu di cuci bersih sebelum pencampuran beton. Kadar lumpur pada agregat halus dan kasar dapat dilihat pada Tabel 4 di bawah:

Tabel 4. Pengujian Kadar Lumpur Agregat

\begin{tabular}{|c|c|c|c|}
\hline Material & $\begin{array}{c}\text { Kadar } \\
\text { Lumpur } \\
(\%)\end{array}$ & Spesifikasi & Ket \\
\hline $\begin{array}{c}\text { Pasir } \\
\text { Tangkiling }\end{array}$ & 5,57 & $\begin{array}{c}\text { Maks 5\% } \\
\text { SK SNI } \\
\text { S-04-1989- } \\
\text { F) }\end{array}$ & $\begin{array}{c}\text { Tidak Masuk } \\
\text { (Agregat } \\
\text { dicuci terlebih } \\
\text { dahulu } \\
\text { sebelum } \\
\text { pencampuran) }\end{array}$ \\
\hline Batu & 0,93 & $\begin{array}{c}\text { Maks 1\% } \\
\text { (SK SNI } \\
\text { S-04-1989- } \\
\text { Merak }\end{array}$ & $\begin{array}{c}\text { Agregat } \\
\text { dicuci terlebih } \\
\text { dahulu } \\
\text { sebelum } \\
\text { pencampuran) }\end{array}$ \\
\hline
\end{tabular}

Sumber: Data uji laboratorium 2018

\section{Kadar Air}

Apabila tidak dalam keadaan jenuh kering permukaan proporsi campuran harus dikoreksi kandungan dalam air agregat. Hasil pemeriksaan dapat dilihat pada Tabel 5 berikut. 
Tabel 5. Kadar Air Agregat

\begin{tabular}{|c|c|}
\hline Material & Kadar Air (\%) \\
\hline Pasir Tangkiling & 2,59 \\
\hline Batu Merak & 2,24 \\
\hline
\end{tabular}

Sumber: Data uji laboratorium 2018

\section{Keausan Agregat Kasar}

Berdasarkan hasil pengujian ukuran butir digunakan Metode B untuk melakukan pengujian keausan agregat berdasarkan SNI 03-2824-2000 dengan menggunakan mesin Los Angeles. Dan didapat hasil dari pengujian abrasi agregat kasar (batu merak) memiliki keausan 31,60\%, dan memenuhi syarat yang diijinkan untuk pencampuran beton yaitu $<40 \%$.

\section{Perhitungan Komposisi Campuran}

Perhitungan campuran beton K-350 berdasarkan SNI 03-2824-2000 untuk tiap per $\mathrm{m}^{3}$ ditunjukkan pada Tabel 6 berikut:

Tabel 6. Perhitungan Pencampuran Beton per $\mathrm{m}^{3}$

\begin{tabular}{|c|l|lc||}
\hline \hline No & \multicolumn{1}{|c|}{ Uraian } & \multicolumn{2}{|c|}{ Nilai } \\
\hline \hline 1 & $\begin{array}{l}\text { Kuat tekan yang } \\
\text { disyaratkan (pada umur } \\
\text { 28 hari) }\end{array}$ & 35,000 & $\mathrm{~N} / \mathrm{mm}^{2}$ \\
\hline 2 & Deviasi standart & 7,500 & $\mathrm{~N} / \mathrm{mm}^{2}$ \\
\hline 3 & Nilai tambah (margin) & 12,300 & $\mathrm{~N} / \mathrm{mm}^{2}$ \\
4 & $\begin{array}{l}\text { Kekuatan rata-rata } \\
\text { yang ditargetkan }\end{array}$ & 47,300 & $\mathrm{~N} / \mathrm{mm}^{2}$ \\
\hline 5 & $\begin{array}{l}\text { Jenis } \\
\text { semen } \quad: \text { halus }\end{array}$ & PC & \\
\hline 6 & \begin{tabular}{l} 
Jenis $\begin{array}{l}\text { Agregat : kemen } \\
\text { agrar }\end{array}$ \\
\hline 7
\end{tabular} & 0,480 & \\
\hline Faktor air $\quad$ maksimum & 0,600 & \\
\hline 8 & Slump & $60-180$ & $\mathrm{~mm}$ \\
\hline 9 & $\begin{array}{l}\text { Ukuran agregat } \\
\text { maksimum }\end{array}$ & 40,000 & $\mathrm{~mm}$ \\
\hline 10 & Kadar air bebas & 205,000 & $\mathrm{Kg} / \mathrm{m}^{3}$ \\
\hline 11 & Kadar semen & 427,083 & $\mathrm{Kg} / \mathrm{m}^{3}$ \\
\hline 12 & $\begin{array}{l}\text { Kadar semen } \\
\text { maksimum }\end{array}$ & 427,083 & $\mathrm{Kg} / \mathrm{m}^{3}$ \\
\hline
\end{tabular}

\begin{tabular}{||c|l|ll||}
\hline No & \multicolumn{1}{|c|}{ Uraian } & \multicolumn{2}{c|}{ Nilai } \\
\hline 13 & Kadar semen minimum & $275,000 \quad \mathrm{Kg} / \mathrm{m}^{3}$ \\
\hline 14 & $\begin{array}{l}\text { Faktor air semen yang } \\
\text { disesuaikan }\end{array}$ & - & \\
\hline 15 & $\begin{array}{l}\text { Susunan besar butir } \\
\text { agregat halus }\end{array}$ & Daerah No. III \\
\hline 16 & $\begin{array}{l}\text { Persen bahan lebih } \\
\text { halus dari 4,8 mm }\end{array}$ & $33,00 \quad \%$ \\
\hline 17 & $\begin{array}{l}\text { Berat jenis relatif, } \\
\text { agregat (kering } \\
\text { permukaan) }\end{array}$ & 2,667 & $\mathrm{Kg} / \mathrm{m}^{3}$ \\
\hline 18 & Berat jenis beton & 2,450 & $\mathrm{Kg} / \mathrm{m}^{3}$ \\
\hline 19 & $\begin{array}{l}\text { Kadar agregat } \\
\text { gabungan }\end{array}$ & $1.817 .917 \mathrm{Kg} / \mathrm{m}^{3}$ \\
\hline 20 & Kadar agregat halus & 599,913 & $\mathrm{Kg} / \mathrm{m}^{3}$ \\
\hline 21 & Kadar agregat kasar & $1.218,004 \mathrm{Kg} / \mathrm{m}^{3}$ \\
\hline
\end{tabular}

Tabel 6. Proporsi Campuran (Setelah Koreksi Air)

\begin{tabular}{|c|c|c|c|c|}
\hline $\begin{array}{c}\text { Banyaknya } \\
\text { Bahan }\end{array}$ & $\begin{array}{c}\text { Semen } \\
(\mathrm{kg})\end{array}$ & $\begin{array}{c}\text { Air } \\
(\mathrm{kg}) \\
\text { atau } \\
(\text { liter })\end{array}$ & $\begin{array}{c}\text { Agregat } \\
\text { Halus } \\
(\mathrm{kg})\end{array}$ & $\begin{array}{c}\text { Agregat } \\
\text { Kasar } \\
(\mathrm{kg})\end{array}$ \\
\hline $\begin{array}{c}\text { Tiap per } \\
\mathrm{m}^{3}\end{array}$ & 427,08 & 214,14 & 611,83 & $1.072,73$ \\
\hline
\end{tabular}

\section{Kuat Tekan Beton}

Adapun karakteristik beton K-350 tanpa dan dengan menggunakan admixture dapat ditunjukan pada tabel berikut:

Tabel 8. Karakteristik Beton K-350 Tanpa Dan Dengan Menggunakan Admixture

\begin{tabular}{|c|c|c|c|}
\hline \multirow{2}{*}{ Campuran } & Berat $(\mathrm{kg})$ & $\begin{array}{c}\text { Kuat } \\
\text { Tekan } \\
\left(\mathrm{kg} / \mathrm{cm}^{2}\right)\end{array}$ & \multirow{2}{*}{$\begin{array}{c}\text { Rata-rata } \\
\left(\mathrm{kg} / \mathrm{cm}^{2}\right)\end{array}$} \\
\hline \multirow{3}{*}{ Normal } & 8,432 & 344,53 & \multirow{2}{*}{350,58} \\
\cline { 2 - 3 } & 8,135 & 353,60 & \\
\cline { 2 - 3 } & 8,255 & 353,60 & \\
\hline $\begin{array}{c}0,25 \\
\text { liter/50 kg } \\
\text { semen }\end{array}$ & 8,366 & 358,13 & \multirow{2}{*}{362,67} \\
\cline { 2 - 3 } $\begin{array}{c}0,5 \\
\text { liter/50 kg } \\
\text { semen }\end{array}$ & 8,233 & 367,20 & \multirow{2}{*}{373,24} \\
\cline { 2 - 3 } $\begin{array}{c}0,75 \\
\text { liter/50 kg } \\
\text { semen }\end{array}$ & 8,353 & 362,67 & 380,80 \\
\hline
\end{tabular}




\section{PENUTUP}

\section{Kesimpulan}

Berdasarkan hasil penelitian, maka dapat disimpulkan bahwa:

1) Komposisi untuk beton mutu K-350 dibutuhkan semen seberat $427.08 \mathrm{~kg}, 214.14$ liter air, agregat halus sebanyak $611.83 \mathrm{~kg}$ dan agregat kasar sebanyak $1072.73 \mathrm{~kg}$ untuk tiap $\mathrm{m}^{3}$.

2) Nilai kuat tekan beton mutu sedang K-350 tanpa bahan admixture sebesar $350,58 \mathrm{~kg} / \mathrm{cm}^{2}$, sedangkan dengan bahan tambah admixture 0,25 liter $/ 50 \mathrm{~kg}$ semen sebesar $362,67 \mathrm{~kg} / \mathrm{cm}^{2}$ dan untuk 0,5 liter $/ 50 \mathrm{~kg}$ semen sebesar 373,24 $\mathrm{kg} / \mathrm{cm}^{2}$ dan untuk 0,75 liter $/ 50 \mathrm{~kg}$ semen sebesar $379,29 \mathrm{~kg} / \mathrm{cm}^{2}$.

3) Perbandingan nilai kuat tekan beton tanpa tambahan admixture terjadi kenaikan 3,45\% pada penambahan 0,25 liter $/ 50 \mathrm{~kg}$ semen, $6,47 \%$ pada penambahan 0,5 liter $/ 50 \mathrm{~kg}$ semen dan $8,19 \%$ pada penambahan 0,75 liter $/ 50 \mathrm{~kg}$ semen.

\section{Saran}

Berdasarkan kesimpulan hasil penelitian ini maka disarankan agar perlu dilakukannya penelitian lanjutan untuk mengetahui batasan maksimal penggunaan tambahan admixture Master Rhebuild 6 pada campuran beton

\section{DAFTAR PUSTAKA}

Badan Standarisasi Nasional, (2002), SNI 03-28472002 Tata Cara Perhitungan Struktur Beton Untuk Bangunan Gedung.

Badan Standarisasi Nasional, (2000), SNI 03-28342000. Tata Cara Pembuatan Rencana Campuran Beton Normal

Badan Standarisasi Nasional, (2004), SNI 15-20492004. Semen Portland

Lydiasari, Henny, (2009), Optimasi Penambahan Admixture LSC 309 dan Rheomac SF100-MBSF Pada Beton Mutu Tinggi
Tjokrodimuljo, Kardiyono, (1992). Teknologi Beton, Yogyakarta; Biro Penerbit Universitas Gadjah Mada. 